\title{
Appropriate approach to a patient alert in a patient undergoing biventricular implantable cardioverter defibrillator battery
}

\author{
Tolga Aksu*, Tumer Erdem Guler and Sedar Bozyel \\ University of Health Sciences, Kocaeli Derince Education and Research Hospital, Department of Cardiology, Kocaeli, Turkey
}

\begin{abstract}
We reported a 46-year-old man presenting to our outpatient department because of audible alerts by his biventricular implantable cardioverter-defibrillator due to high lead and shock impedances. High impedance was associated with fluid and blood accumulation in the pacemaker header. Immediately after the pacemaker pocket was opened and drained the fluid lead and shock impedances were normalized.
\end{abstract}

\section{Introduction}

Implantable cardioverter defibrillators (ICD) are well accepted devices for prevention of sudden cardiac death [1]. Because of the increase in appropriate indications, the use of ICDs has increased remarkably over the past years. Proper functioning of the devices is vital for patient welfare, because dysfunction can cause fatal proarrhythmia [2]. Herein, we tried to discuss appropriate approach to a patient alert in a patient with new implanted biventricular ICD.

\section{Case report}

A 46-year-old man presented to our outpatient department because of audible alerts by his biventricular implantable cardioverterdefibrillator (BICD) starting about 3 days ago. The initial device (Medtronic 7218D) had been replaced with BICD (St Jude Promote +) 4 days ago due to NYHA class 3 symptoms. In his medical history, VVI ICD had implanted for primary prevention of ischemic cardiomyopathy in 2008. Because of the inappropriate coronary sinus anatomy, unipolar coronary sinus electrode had been implanted epicardially. Device interrogation disclosed that the alert had been triggered by a high coronary sinus lead impedance $>2000 \Omega$ and by a high voltage lead (shock) impedance $>200 \Omega$ (Figure 1). There was no connection defect or lead fracture in fluoroscopically evaluation. Epicardial lead was detected in left ventricular posterolateral wall.

Although the fluoroscopy was unsuspicious, surgical generator and lead revision was planned. Immediately after the pacemaker pocket was opened, we observed that the fluid with bloody characteristics was drained from the pacemaker pocket. Following this procedure, it was detected that the coronary sinus lead impedance and shock impedance were normalized (Figure 2).

\section{Discussion}

High lead and shock impedance are common problems for implantable cardiac devices [3]. It is usually caused either by external compression or internal motion of conducting cables. It has been showed that lead integrity may be affected by exposing conductors directly to blood or tissue due to the silicone lead body and inner fluoropolymer insulation have been breached completely [4]. While this situation often results with low lead impedance, we speculated that fluid or blood in the pacemaker header may be a potential cause of high lead or shock impedance. To deal with this rare complication, the capsule inside the device pocket should be opened because a new device, even if a similar sized to the one removed, cannot fit perfectly in the original pocket. Thus, it may cause fluid or blood accumulation. If the capsule inside the device pocket is not opened, absorption of accumulated fluid may not be possible.

In conclusion, we have described a case of patient alert due to fluid accumulation. In ICD patients, the existence of this rare complication must be kept in mind.

Correspondence to: Tolga Aksu, MD, Associate Professor of Cardiology, FESC, Kocaeli, Turkey, Zip code: 41100, Tel: +90 53199032 78; Fax: +90 26231780 00; E-mail: aksutolga@gmail.com

Received: November 18, 2017; Accepted: December 07, 2017; Published: December 11, 2017 


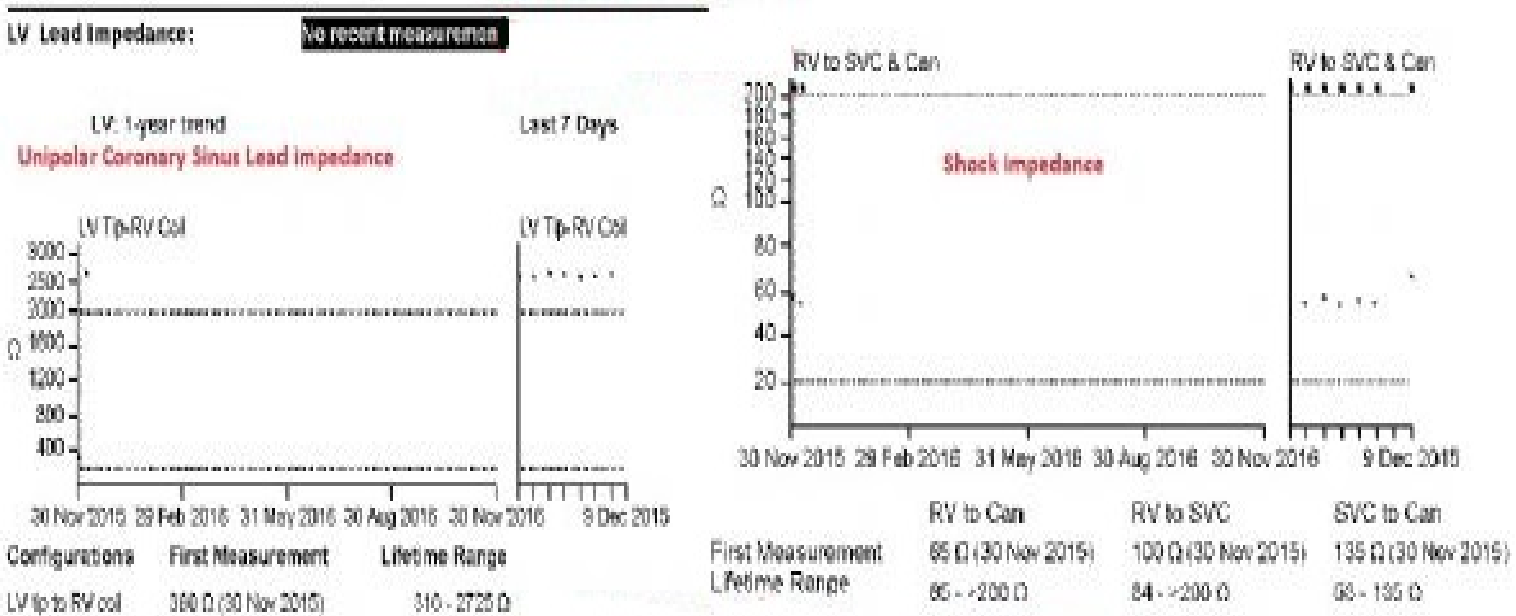

Figure 1. Graphic displays of unipolar coronary sinus lead impedance measurement as well as shock impedance from an implanted St Jude Promote + biventricular implantable cardioverterdefibrillator. This event counters report measurement made on the admission. Please note high lead and shock impedances.

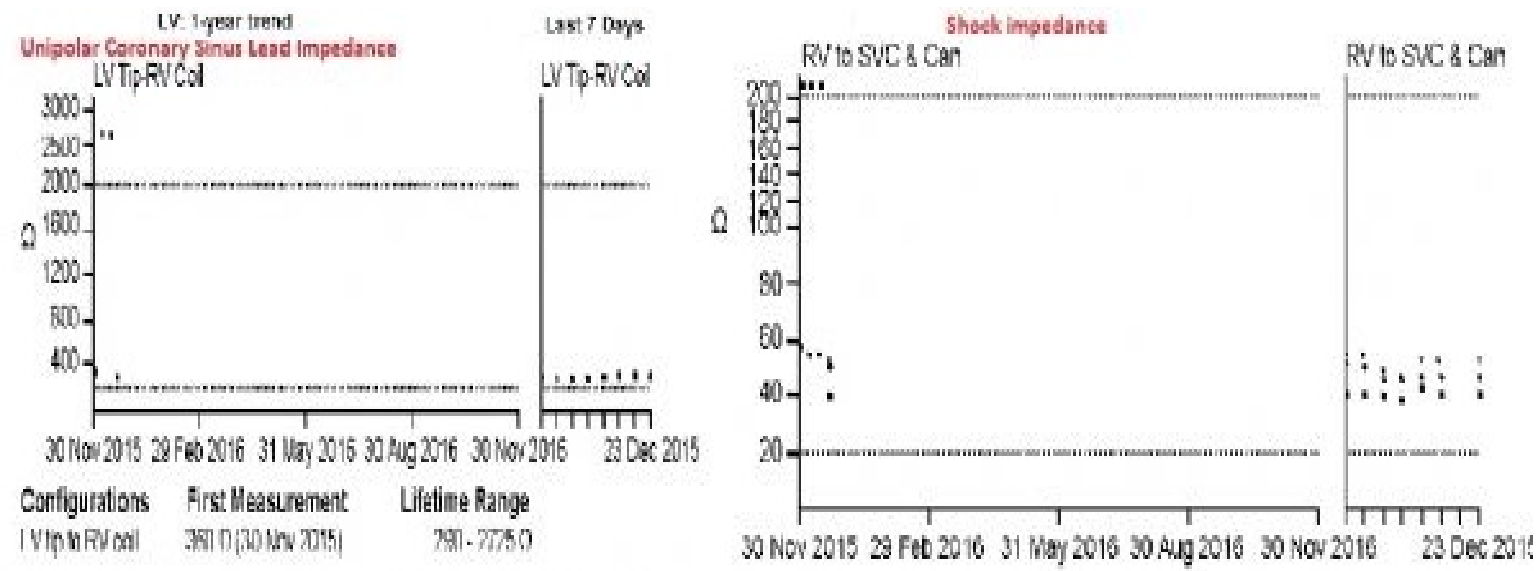

Figure 2. Graphic displays of unipolar coronary sinus lead impedance measurement as well as shock impedance from an implanted St Jude Promote + biventricular implantable cardioverterdefibrillator. This event counters report measurement made after fluid discharge. Please note returning lead and shock impedances to normal levels.

\section{References}

1. Al-Khatib SM, Stevenson WG, Ackerman MJ, Gillis AM, Bryant WJ, et al., (2017) AHA/ACC/HRS Guideline for Management of Patients With Ventricular Arrhythmias and the Prevention of Sudden Cardiac Death: A Report of the American College of Cardiology/American Heart Association Task Force on Clinical Practice Guidelines and the Heart Rhythm Society. Heart Rhythm pii: S1547-5271:31250-X.

2. Vollmann D, Luthje L, Vonhof S, et al., (2005) Inappropriate therapy and fatal proarrhythmia by an implantable cardioverter-defibrillator. Heart Rhythm 2: 307-309.
3. Kleemann T, Becker T, Doenges K, Vater M, Senges J et al., (2007) Annual rate of transvenous defibrillation lead defects in implantable cardioverter-defibrillators over a period of $>10$ years. Circulation 115: 2474-2480

4. Ellenbogen K, Kay GN, Lau CP, Wilkoff BL (2007) Clinical Cardiac Pacing, Defibrillation and Resynchronization Therapy. 3rd edition. Saunders Elsevier: 849850

Copyright: (C2017 Aksu T. This is an open-access article distributed under the terms of the Creative Commons Attribution License, which permits unrestricted use, distribution, and reproduction in any medium, provided the original author and source are credited. 